\title{
Inactivation of Bacillus subtilis Spores in Orange Juice and the Quality Change by High Electric Field Alternating Current
}

\author{
Kunihiko UEMURA ${ }^{1 *}$, Isao KOBAYASHI ${ }^{1}$ and Takashi INOUE ${ }^{2}$ \\ ${ }^{1}$ Food Engineering Division, National Food Research Institute, National Agriculture and Food Research \\ Organization (Tsukuba, Ibaraki 305-8642, Japan) \\ ${ }^{2}$ Product Research \& Development Department, Pokka Corporation \\ (Kitanagoya, Aichi 481-8515, Japan)
}

\begin{abstract}
Heat treatment is commonly used to inactivate micro-organisms in liquid foods in order to improve food safety and extend shelf life. However, using heat treatment to kill spores also thermally damages the food, which can adversely affect the flavor and lead to loss of nutrients. We have developed an apparatus to apply a high electric field alternating current (HEF-AC) that inactivates heat-resistant microbe spores in liquid food while preserving the freshness of raw food. In this study, HEF-AC was applied to inactivate Bacillus subtilis spores in fresh orange juice. As a result, B. subtilis spores were reduced four logarithmic orders of magnitude. The purpose of this work was to clarify the quality change of treated juice. To achieve this purpose, we used an ultra-high-temperature (UHT) treatment for comparison. Five selected quality components of orange juice treated with HEF-AC maintained higher values than when treated with UHT while having an equal inactivation effect.
\end{abstract}

Discipline: Food

Additional key words: flavor, high electric field AC, nutrient

\section{Introduction}

Heating has been generally used for inactivating microorganisms in foods, but heat treatment of foods also destroys delicate fragrance components and useful functionality components. Therefore, a high electric field pulse ${ }^{9}$, a high-intensity light pulse and radioactive rays have been researched and developed both domestically and abroad as non-thermal inactivation methods, but these methods are expensive and their use is limited to food industry applications that demand large-scale processing.

Internal heating caused by an electric current has been used for 100 years and can be divided into two types, microwave heating and ohmic heating. Microwave heating technology has spread from industrial use to home use with products employing electromagnetic energy at a frequency of $2.45 \mathrm{GHz}$ for heating food. The ohmic heating method is older than microwave heating and was reportedly used to inactivate micro-organisms in milk in $1920^{1}$. However, ohmic heating using a high frequency of around $20 \mathrm{kHz}$ has become a useful technology in the food industry and has been used to process fish cake since 1990 because of the increased stability and increased energy efficiency. It had been believed for a long time that micro-organisms in food were inactivated by the electrical effects of ohmic heating. However, Palaniappan et al. reported that ohmic heating did not induce electrical effects for inactivation ${ }^{10}$, and Imai et al. reported on the characteristics of the breakdown of the cell membrane when an electric field was used in the ohmic heating of vegetables, where the voltage in a cell was close to $1 \mathrm{~V}^{7}$.

A high electric field pulse, a non thermal inactivation technology, inactivates micro-organisms in foods using high-voltage pulse sterilization with a very narrow pulse width (less than $10 \mu \mathrm{s}$ ) and high electric field strength (more than $10 \mathrm{kV} / \mathrm{cm}$ ).

A potential difference is induced between the two ends of the cell membrane when a high-strength electric field is used on a cell for sterilization. A hole subsequently opens in a local fragile site of the membrane by electricity perforation through a mechanism called electroporation. Hulsheger et al. reduced Escherichia coli two orders of magnitude when they applied 30 pulses of $30 \mu$ s width in a $12 \mathrm{kV} / \mathrm{cm}$ 
electric field ${ }^{6}$. Qin et al. succeeded in reducing Escherichia coli six orders of magnitude by applying 60 pulses with 3 $\mu$ s width in a $40 \mathrm{kV} / \mathrm{cm}$ field ${ }^{12}$. Pothakamury et al. applied 50 pulses at $16 \mathrm{kV} / \mathrm{cm}$ to Staphylococcus aureus in a food model of milk and reduced the bacteria by four orders of magnitude ${ }^{11}$. Electroporation is known to be generated on a cell membrane when an electric potential exceeding 1 $\mathrm{V}$ per cell is applied ${ }^{13,14}$. Uemura et al. developed a high electric field alternating current (HEF-AC) technology that combined ohmic heating and a high electric field. HEF-AC was originally designed to inactivate Escherichia coli in liquid foods by Uemura and Isobe ${ }^{15}$. The inactivation was caused by a combination of electric field effect and Ohmic heating effect. Geveke et al. applied a $20 \mathrm{kHz}, 18 \mathrm{kV} / \mathrm{cm}$ electric field called a radio frequency electric field to $E$. coli in apple juice at a moderately low temperature of $50^{\circ} \mathrm{C}$, reducing the E. coli to $3 \log$ by the high electric field effect. High-voltage pulses were not able to inactivate spores ${ }^{5}$. Uemura et al. used a HEF-AC with an electric field of 10 $\mathrm{kV} / \mathrm{cm}$ on Bacillus subtilis spores that were added to orange juice and reduced the number of bacteria by four orders of magnitude by heating the electrode exit to $120^{\circ} \mathrm{C}^{16}$. Inoue et al. used a HEF-AC on various microorganisms, including the highly heat-resistant spores that were added to a model liquid, and reduced the bacteria by over three orders of magnitude ${ }^{8}$. With HEF-AC, rapid heating at temperatures higher than $100^{\circ} \mathrm{C}$ was required to inactivate $B$. subtilis spores in a short time. In this study, we inactivate $B$. subtilis spores in a orange juice by a practical scale HEF-AC and compare the quality change of HEF-AC treated orange juice with a ultra high temperature (UHT) treated one.

\section{Materials and methods}

\section{Micro-organism strain}

The strain of B. subtilis (JCM2744) used in this study was obtained from the Japanese Collection of Microorganisms.

\section{Orange juice}

Frozen concentrated orange juice from Louis Dreyfus Citrus (Brazil) was purchased from Nisshin Trading Co. The orange juice used in the experiment was obtained by dilution to five times with distilled water and had a Brix of 11.0 and $\mathrm{pH}$ of 4.0. The juice contained 9\% pulp (analysis by USDA method).

\section{HEF-AC setup}

Figure 1 outlines the HEF-AC setup. Raw orange juice in a tank is fed at a constant flow rate of $100 \mathrm{~L} /$ hour. The internal pressure in the pipe between the feeder pump and the relief valve is controlled at $0.5 \mathrm{MPa}$ by the pressure of the valve. The AC power supply had a $2,000 \mathrm{~V}$ maximum output voltage, $50 \mathrm{~kW}$ maximum output power and a $20 \mathrm{kHz}$ square-wave AC. An electric treatment unit was constructed with a parallel plate electrode made of titanium $(6.0 \mathrm{~mm}$ in width and $32 \mathrm{~mm}$ in length, with $4.0 \mathrm{~mm}$ between electrodes) and a surrounding insulator made of Teflon (Fig. 2).

\section{UHT setup}

An ultra-high-temperature (UHT) sterilizer (25 HV hybrid UHT/LTST, Micro Thermic Inc., USA) was used for comparison. Table 1 presents the temperature history of samples for HEF-AC treatment and UHT treatment.

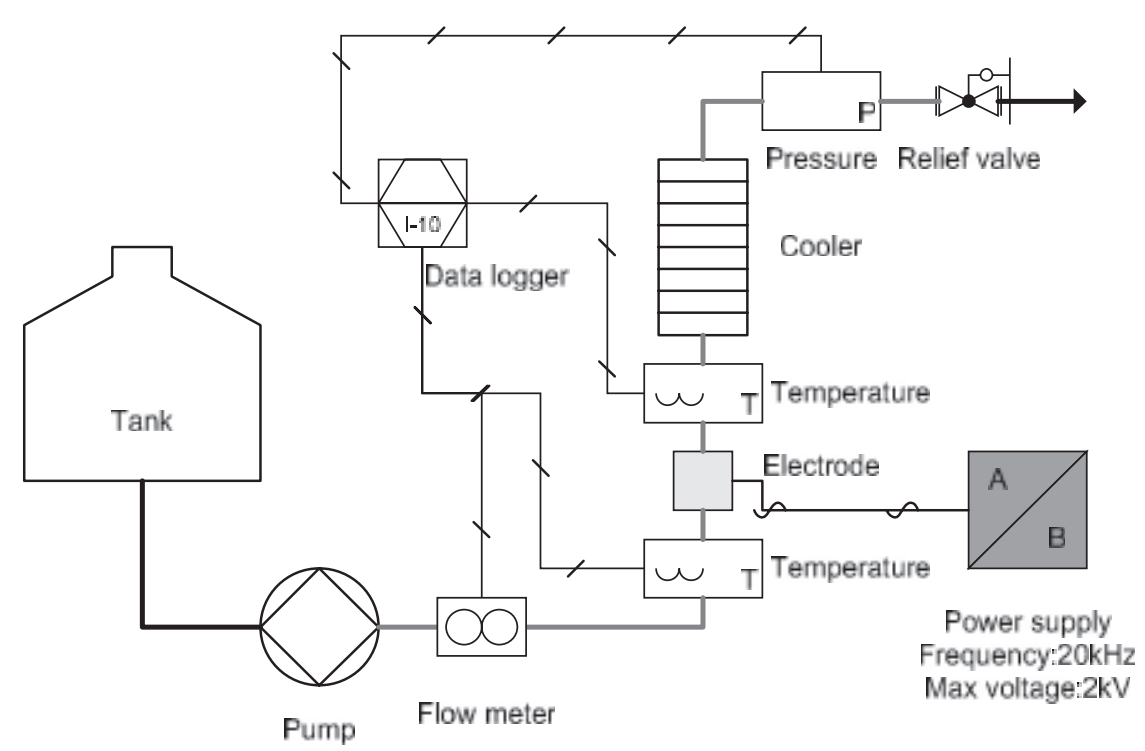

Fig. 1. HEF-AC setup 


\section{Analysis of quality}

\section{(1) Linalool and limonene}

Aromatic hydrocarbons linalool and limonene in the orange juice were measured as follows. Solid-phase microextraction was used to extract analytes from the headspace above the orange juice. Aromatic hydrocarbons were adsorbed by Solid Phase Micro Extract (SPME). Ten $\mathrm{mL}$ samples and $3 \mathrm{~g}$ of salt in a flat-bottom vial (Agilent) were heated to $50^{\circ} \mathrm{C}$, and the aromatic gas in the headspace was then adsorbed onto SPME resin (SUPELCO, SPME Fiber Assembly $2 \mathrm{~cm} \mathrm{-} \mathrm{50/30} \mathrm{\mu m} \mathrm{DVB/Carboxen/PDMS)} \mathrm{for} 15$ min. A gas chromatograph-mass spectrometer (GC-MS) was performed by selected-ion recording (SIR) on a Mass Selective Detector (5972, Agilent, USA) equipped with a gas chromatograph (GC6890, Agilent, USA) and a capillary (DB-Wax $60 \mathrm{~m}, 0.25 \mathrm{~cm}$ inside diameter, J\&W Scientific). The oven was programmed at $50^{\circ} \mathrm{C}(2 \mathrm{~min})$ and heated to $250^{\circ} \mathrm{C}$ at $5^{\circ} \mathrm{C} / \mathrm{min}$, with a final hold time of $5 \mathrm{~min}$. Samples were injected in pulsed splitless mode with $\mathrm{He}$ as the carrier gas at a flow rate of $1.0 \mathrm{~mL} / \mathrm{min}$. Total extract yields were determined by gas chromatography flame ionization detection (GC-FID) on a Hewlett Packard 6890 GC system, and individual compounds were quantified using corrected

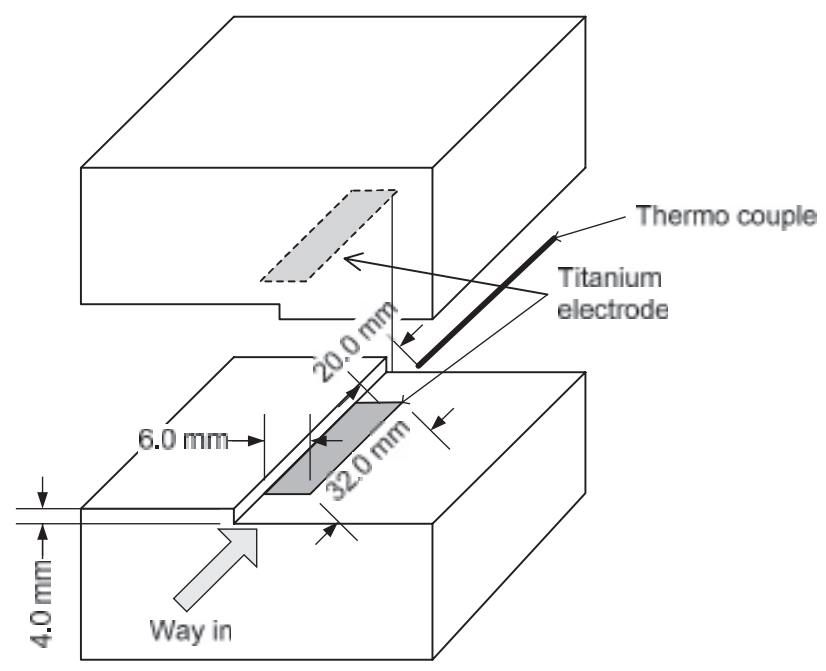

Fig. 2. Longitudinal section of electrode unit
GC-MS (SIR) or full-scan signals with d14-para-terphenyl (D14) and 3-methylhenicosane (aC22) as internal standards. (2) $\beta$-carotene

$\beta$-carotene was analyzed using high-performance liquid chromatography (HPLC) including a VP Diode Array Detector (SPD-M10A, Shimadzu, Japan; refer to the method of Khachik et al.). The analytical and semi-preparative separations employed a combination of isocratic and gradient chromatography. An isocratic mixture of acetronitrile (85\%), methanol (10\%), dichloromethane $(2.5 \%)$, and hexane $(2.5 \%)$ at time 0 was followed by a linear gradient beginning at time $10 \mathrm{~min}$ and completed at time $40 \mathrm{~min}$. The final composition of the gradient mixture was acetonitrile (45\%), methanol (10\%), dichloromethane $(22.5 \%)$, and hexane $(22.5 \%)$. The chromatographic analyses were monitored at $470 \mathrm{~nm}$. Analytical separations used a YMC-Pack (250 mm length $\times 4.6 \mathrm{~mm}$ i.d.) ODS-A $(5 \mu \mathrm{m}$ spherical particle, $12 \mathrm{~nm}$ hole) column (YMC Co. Ltd., Japan) at $30^{\circ} \mathrm{C}$.

\section{(3) Hesperidin}

Hesperidin was analyzed using HPLC (SPD-M10A with VP Diode Array Detector, Shimadzu, Japan) with a column (ODS-A, YMC). A methanol-phosphate buffer $(30: 70 \mathrm{v} / \mathrm{v})$ was used as the mobile phase. The column had an average particle size of $5 \mu \mathrm{m}$ and a $250 \mathrm{~mm}$ length $\times$ $4.6 \mathrm{~mm}$ i.d. Shim-pack CLC-ODS analysis was run under isocratic elution with a flow rate of $1.0 \mathrm{~mL} / \mathrm{min}$ at $25^{\circ} \mathrm{C}$ and an injection volume for all samples of $25 \mu \mathrm{L}$. The effluent was monitored by an ultraviolet-visible detector (UV-vis Detector, Shimadzu, Japan) at $280 \mathrm{~nm}$.

\section{(4) L-ascorbic acid}

The L-ascorbic acid concentration was measured using HPLC (SPD-M10A including VP Diode Array Detector, Shimadzu, Japan) with a column (Polyamine II, YMC, Japan) at $250 \mathrm{~nm}$ wavelength. Two and one half grams of orange juice were mixed with $2.5 \mathrm{~mL}$ of $8 \%$ metaphosphoric acid solution to stabilize ascorbic acid and then diluted to $10 \mathrm{~mL}$ with ethanol. The mixture was centrifuged at 3,000 rpm for $10 \mathrm{~min}$. Then $800 \mu \mathrm{L}$ of the supernatants was mixed with $800 \mu \mathrm{L}$ of $2 \%$ metaphosphoric acid and filtered through a $0.45 \mu \mathrm{m}$ membrane filter. A $20 \mu \mathrm{L}$ aliquot of the samples was injected into the HPLC. Separation was performed using a Polyamine II column $(250 \mathrm{~mm}$ length $\times 4.6 \mathrm{~mm}$

Table 1. Liquid flow parameters for HEF-AC and UHT

\begin{tabular}{lcccc}
\hline \hline & $\begin{array}{c}\text { Flow rate } \\
{[\mathrm{L} / \mathrm{h}]}\end{array}$ & $\begin{array}{c}\text { Rising time } \\
{[\mathrm{s}]}\end{array}$ & $\begin{array}{c}\text { Holding time } \\
{[\mathrm{s}]}\end{array}$ & $\begin{array}{c}\text { Cooling time } \\
{[\mathrm{s}]}\end{array}$ \\
\hline $\mathrm{HEF}-\mathrm{AC}$ & 60 & 0.046 & 0.86 & 60 \\
$\mathrm{UHT}_{\mathrm{f}}$ & 156 & 36 & 4.3 & 36 \\
$\mathrm{UHT}_{\mathrm{S}}$ & 78 & 72 & 8.6 & 72 \\
\hline
\end{tabular}

$\mathrm{UHT}_{\mathrm{f}}$ : fast flow.

$\mathrm{UHT}_{\mathrm{S}}$ : slow flow. 
i.d., particle size $5 \mu \mathrm{m}, \mathrm{YMC}$, Japan). The detector was set to $250 \mathrm{~nm}$. A solution consisting of acetonitorile to $50 \mathrm{mM}$ ammonium dihydrogen phosphate at a ratio of $75: 25 \mathrm{v} / \mathrm{v}$ was used as the mobile phase at a flow rate of $1.0 \mathrm{~mL} / \mathrm{min}$.

\section{Results and discussions}

\section{Inactivation of B.subtilis spores}

An electric field of $2.8 \mathrm{kV} / \mathrm{cm}$ to $3.0 \mathrm{kV} / \mathrm{cm}$ was applied to $10^{6} \mathrm{cfu} / \mathrm{mL}$ B. subtilis spores in the orange juice (Fig 2); the outlet temperature and the sterilization effect are presented in Fig. 3. The sterilization effect increased when the electric field strength applied by the HEF-AC increased, and the electrode exit temperature rose from $110^{\circ} \mathrm{C}$ to $120^{\circ} \mathrm{C}$. The sterilization effect increased with increasing outlet temperature, and the spores were reduced by four orders of magnitude at $120^{\circ} \mathrm{C}$.

The B. subtilis spores in orange juice were sterilized and reduced by three (four) orders of magnitude by UHT processing at $110^{\circ} \mathrm{C}$ for $4.3 \mathrm{~s}(8.6 \mathrm{~s})$ holding time (Fig. 4). We compared quality components between the high-strength AC electric field at $120^{\circ} \mathrm{C}$ and the UHT at $110^{\circ} \mathrm{C}$ for $8.6 \mathrm{~s}$. We concluded that $\mathrm{HEF}-\mathrm{AC}$ at $120^{\circ} \mathrm{C}$ is equally effective for inactivating $B$. subtilis spores in orange juice with UHT at $110^{\circ} \mathrm{C}$ for $8.6 \mathrm{~s}$.

\section{Quality change of orange juice}

Figures 5 and 6 present the comparison of the content of linalool and limonene that are fragrance components of orange juice after the HEF-AC and UHT treatments. These results demonstrate that $24 \%$ more linalool and $15 \%$ more limonene remained in the orange juice after HEF-AC treatment than after UHT treatment. Figures 7, 8 and 9 depict the effects on $\beta$-carotene, hesperidin and L-ascorbic acid content in orange juice after HEF-AC treatment and

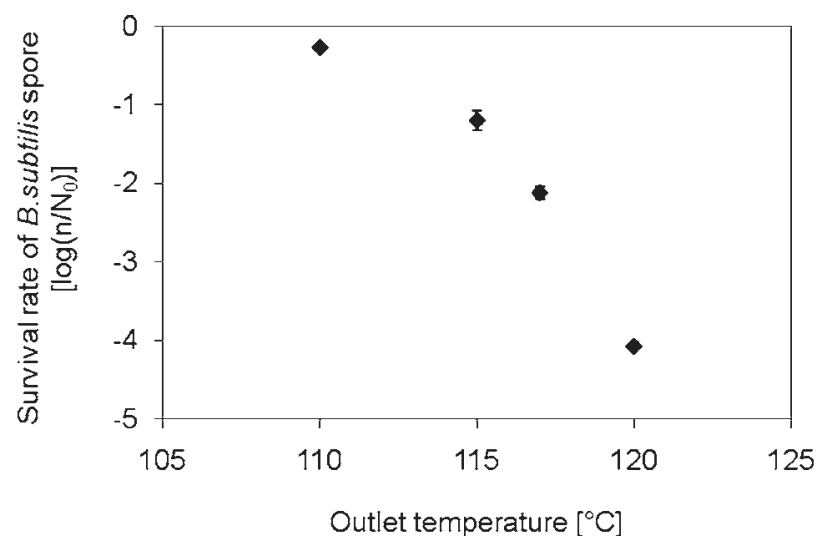

Fig. 3. Viability loss of $B$. subtilis spores in orange juice using HEF-AC at different outlet temperatures

$\mathrm{n}$ : Viable counts at indicated temperature

$\mathrm{N}_{0}$ : Initial viable counts

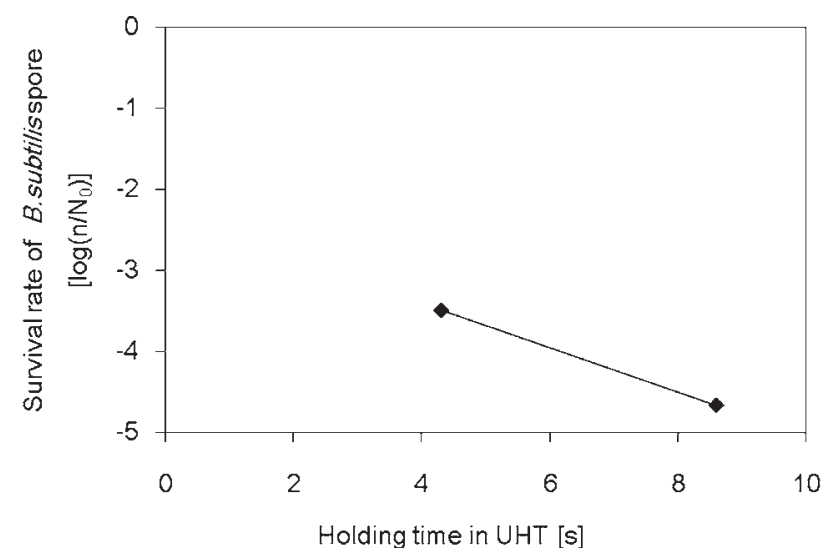

Fig. 4. Viability loss of $B$. subtilis spores in orange juice using UHT at different flow rates

$\mathrm{n}$ : Viable counts at indicated temperature

$\mathrm{N}_{0}$ : Initial viable counts

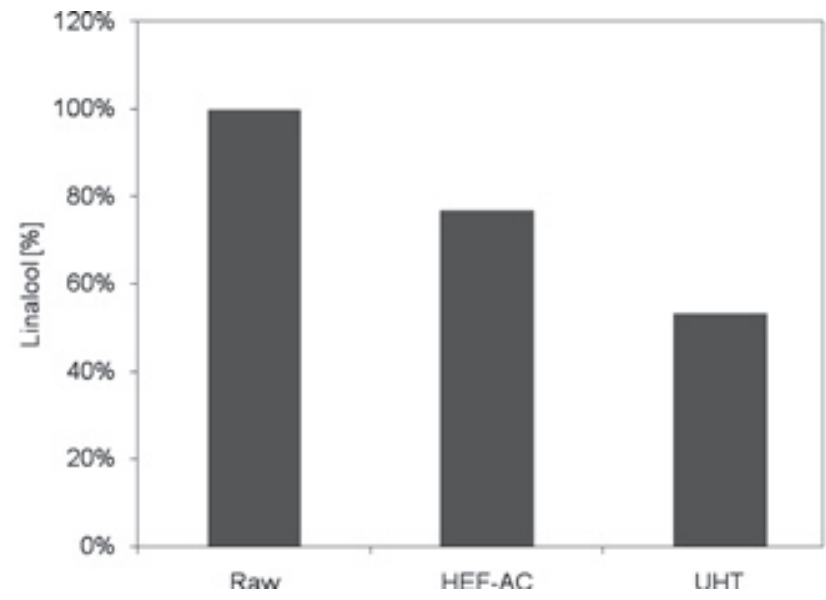

Fig. 5. Change of linalool in orange juice after HEF-AC or UHT

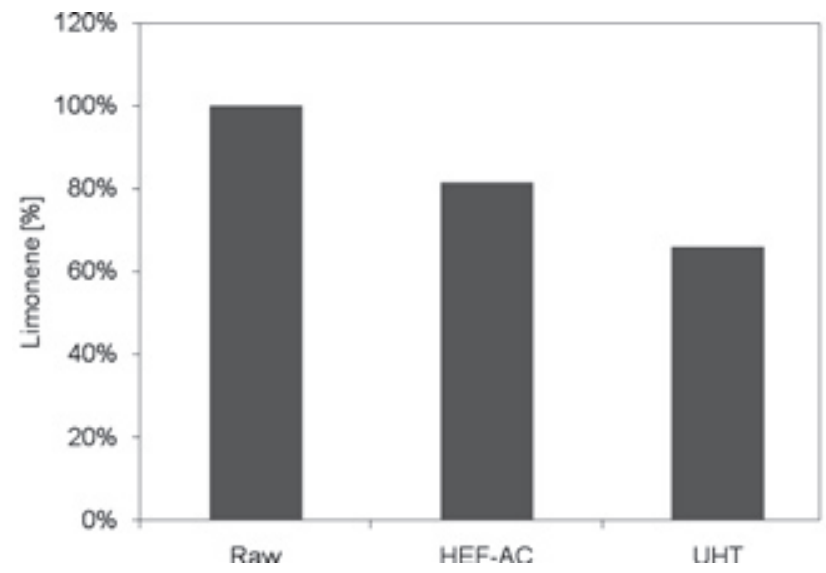

Fig. 6. Change of limonene in orange juice after HEF-AC or UHT 
UHT treatment. These results indicate that $25 \%$ more $\beta$ carotene, $18 \%$ more hesperidin and $8 \%$ more L-ascorbic acid remained in the orange juice after HEF-AC treatment than after UHT treatment.

The results revealed that $\mathrm{HEF}-\mathrm{AC}$ treatment clearly retained more functional components of orange juice compared to conventional UHT treatment. Most likely, this was due to the fact that the holding time, in case of HEF-AC was almost ten times shorter than in the case of UHT treatment, so that HEF-AC preserved these functional components.

\section{Summary}

The HEF-AC technique provided effective inactivation of $B$. subtilis spores in orange juice due to its shorter heating time. We also found that HEF-AC retained more fragrance and nourishment components in orange juice than UHT. In

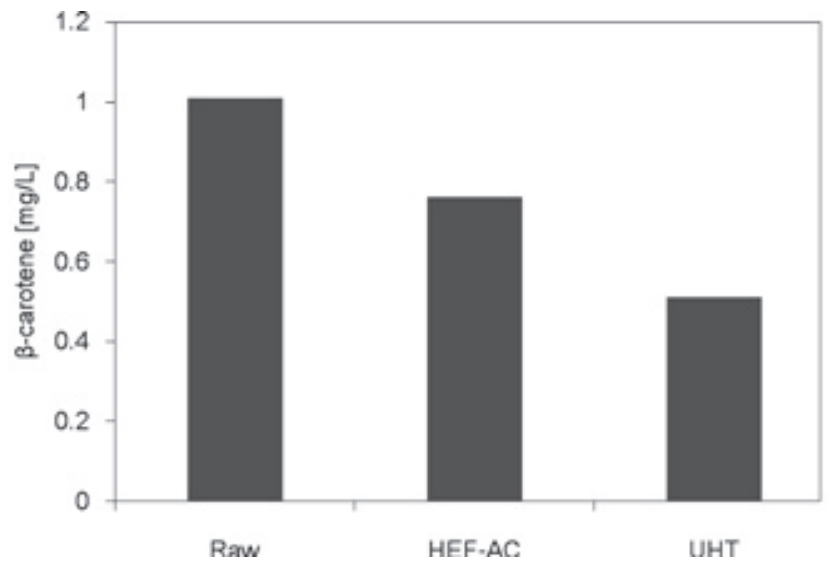

Fig. 7. Change of $\beta$-carotene after HEF-AC or UHT

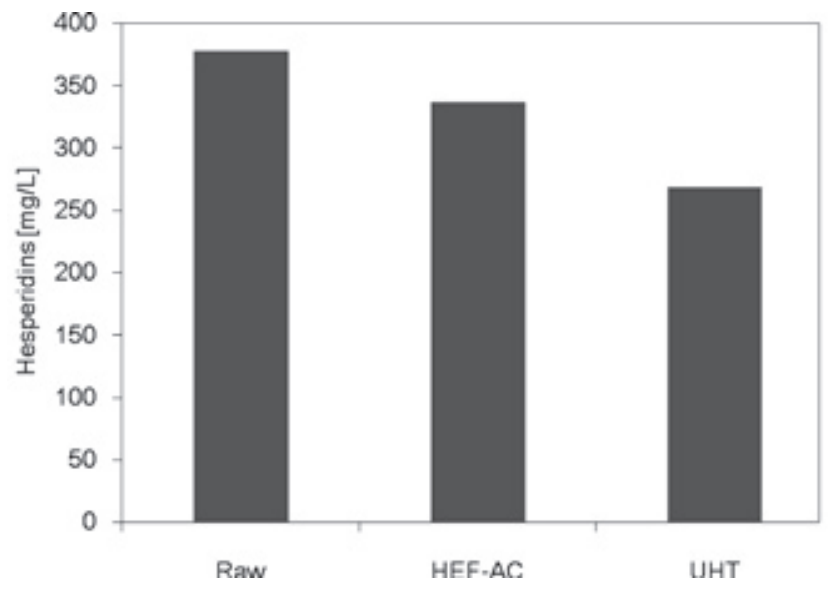

Fig. 8. Change of hesperidins after HEF-AC or UHT

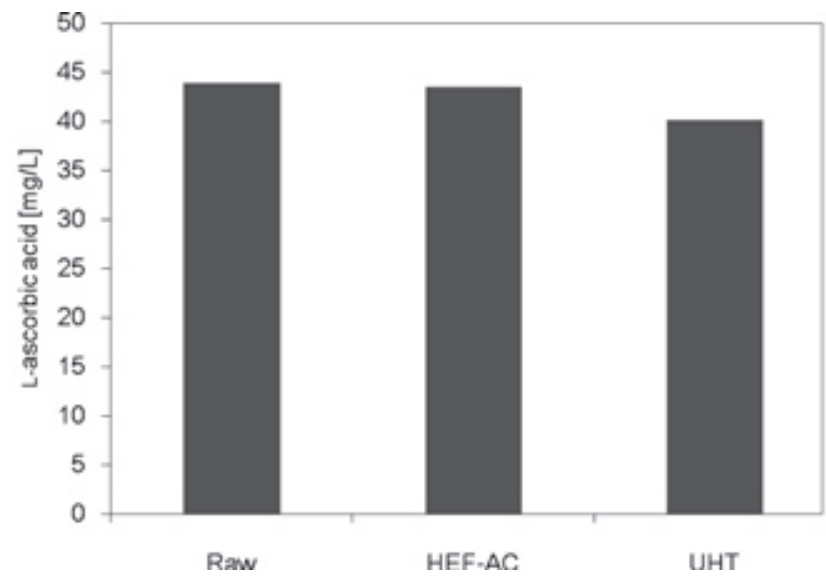

Fig. 9. Change of L-ascorbic acid after HEF-AC or UHT

addition, we confirmed that the HEF-AC technology can be scaled up and can be applied to consecutive processing, making it a suitable inactivation technology for practical use.

\section{Acknowledgments}

We developed the HEF-AC apparatus in cooperation with Pokka Co. at the stage for scaling up to achieve practical use through the cooperation of the Frontier Engineering Co. The authors are grateful to the staff of both companies for their assistance in the experiments.

\section{References}

1. Anderson, A. K. \& Finkelstein, R. (1919) A study of the electro pure process of treating milk. J. Dairy Sci., 2, 374406.

2. Bushnell, H. A, Dunn, J. E. \& Clark, R. W. (1991) High pulsed voltage systems for extending the shelf life of pumpable food products. US Patent 5048404.

3. Castro, A. J., Barbosa-Canovas, G. V. \& Swanson, B. G. (1993) Microbial inactivation of foods by pulsed electric fields. J. Food Process. Preserv., 17, 47-73.

4. Cserhalmi, Z. et al. (2002) Inactivation of Saccharomyces cerevisiae and Bacillus cereus by pulsed electric fields. Innov. Food scene and Emerg. Technol., 3(1), 41-45.

5. Geveke, D. J. et al. (2006) Nonthermal inactivation of $E$. coli in fruit juices using radio frequency electric fields. In Advances in microbial food safety, eds. Juneja, V. K., Cherry, J. P. \& Tunick, M. H., American Chemical Society, Washington DC, 121-139.

6. Hulsheger, H., Potel, J. \& Niemann, E. G. (1983) Electric field effects on bacteria and yeast cells. Radiat. Environ. Biophys., 22, 149-162.

7. Imai, T. Noguchi, A. \& Uemura, K. (1995) Ohmic heating of Japanese white radish. J. Food Science and Technology, 30, 461-472.

8. Inoue, T. et al. (2007) Inactivation of various microorganism 
spores by high electric field AC treatment in saline. Nippon syokuhin kougakkaishi (J. Food. Eng.), 8, 3, 123-130 [In Japanese with English summary].

9. Ohshima, T., Hama, T. \& Sato, M. (2000) Releasing profiles of gene products from recombinant Escherichia coli in a high-voltage pulsed electric field. Biochem. Eng. J., 5, 149155.

10. Palaniappan, S., Sastry, S. K. \& Richter, E. R. (1990) Effects of electricity on microorganisms. J. Food Proc. Preserve, 14, 393-414.

11. Pothakamury, U. R. et al. (1995) Inactivation of Escherichia coli and Staphylococcus aureus in model foods by pulsed electric field technology. Food Research Int., 28, 2, 167171.

12. Qin, B. L. et al. (1995) Pulsed electric field treatment chamber design for liquid food pasteurization using finite element method. Trans. ASAE, 38, 2, 557-565.

13. Sale, A. J. H. \& Hamilton, W. A. (1967) Effect of high electric fields on microorganism. I. Killing of bacteria and yeast. Biochimica et Biophysica Acta, 48, 781-788.

14. Sale, A. J. H. \& Hamilton, W. A. (1968) Effect of high electric fields on microorganisms. 3. Lysis of erythrocytes and protoplasts. Biochimica et Biophysica Acta, 163, 37-43.

15. Uemura, K. \& Isobe, S. (2002) Developing a new apparatus for inactivating Escherichia coli in saline water with high electric field AC. J. Food Engineering, 53, 203-207.

16. Uemura, K. \& Isobe, S. (2003) Developing a new apparatus for inactivating Bacillus subtilis spore in orange juice with a high electric field AC under pressurized conditions. J. Food Engineering, 56, 325-329. 